\title{
Origin of Area Selective Plasma Enhanced Chemical Vapor Deposition of Microcrystalline Silicon
}

\author{
Ghewa Akiki, ${ }^{1}$ Mathieu Frégnaux, ${ }^{2}$ Ileana Florea, ${ }^{1}$ Pavel Bulkin, ${ }^{1}$ Dmitri Daineka, ${ }^{1}$ \\ Sergej Filonovich, ${ }^{3}$ Muriel Bouttemy ${ }^{2}$ and Erik V. Johnson ${ }^{1, a)}$ \\ ${ }^{1}$ LPICM-CNRS, Ecole Polytechnique, Institut Polytechnique de Paris, Route de Saclay, 91120 Palaiseau, \\ France \\ ${ }^{2}$ Institut Lavoisier de Versailles (ILV), Université de Versailles Saint-Quentin en Yvelines, Université \\ Paris-Saclay, CNRS, UMR 8180, 45 avenue des Etats-Unis, 78035 Versailles Cedex, France
}

${ }^{3}$ TOTAL GRP, 2 Place Jean Millier - La Défense 6, 92078 Paris La Défense Cedex, France

a)Electronic mail: ghewa.akiki@polytechnique.edu

\begin{abstract}
Plasma Enhanced Chemical Vapor Deposition of silicon from $\mathrm{SiF}_{4} / \mathrm{H}_{2} / \mathrm{Ar}$ gas mixture is observed on a $\mathrm{SiO}_{\mathrm{x}} \mathrm{N}_{\mathrm{y}}$ surface, while under the same plasma conditions, silicon films do not grow on $\mathrm{AlO}_{\mathrm{x}}$ nor Al surfaces. Transmission electron microscopy confirms that the silicon deposited on $\mathrm{SiO}_{\mathrm{x}} \mathrm{N}_{\mathrm{y}}$ has a microcrystalline structure. After the plasma process, fluorine is detected in abundance on the $\mathrm{AlO}_{\mathrm{x}}$ surface by X-ray photoelectron spectroscopy and energy dispersive X-ray chemical analyses. This suggests that Al-F bonds are formed on this surface, blocking any deposition of silicon on it. In-situ ellipsometry studies show that deposition can be initiated on $\mathrm{AlO}_{\mathrm{x}}$ surfaces by increasing the temperature of the electrodes or increasing the RF plasma power, leading to a loss of selectivity.
\end{abstract}

\section{Introduction}

The development of processes that can limit material deposition to one type of surface area without using lithography have recently gained increased attention from the microelectronics industry. Such processes, called area-selective deposition (ASD), are designed to promote deposition on the "growth" area of a substrate while preventing deposition on a "non-growth" area. Atomic Layer Deposition (ALD) and Chemical Vapor Deposition (CVD) are the most widely-used techniques used to achieve ASD, depositing metals, semiconductors, and insulators ${ }^{1}$. These techniques work either by activating the growth surface, passivating or deactivating the non-growth area surface, adding a co-reagent to the precursors, or treating the surfaces prior to the process in a way to block any deposition or etching ${ }^{2,3}$.

In the case of CVD, the selective epitaxial deposition of semiconductors such as silicon and GaAs has been demonstrated using silicon tetrachloride/hydrogen and an undoped $\mathrm{GaAs}$ source/ $\mathrm{HCl}$ or 
$\mathrm{AsCl}_{3} / \mathrm{H}_{2}$, respectively ${ }^{4,5}$. In these cases, chlorine is the factor that promotes the selectivity, as it can reduce the rate of deposition of $\mathrm{Si}$ and $\mathrm{Ga}^{6}$.

As for metals, selective tungsten deposition has been demonstrated by CVD using $\mathrm{WF}_{6} / \mathrm{H}_{2}$ gases. In this case, bare silicon is considered as a solid reducing agent, as it can lose an electron and dissociate $\mathrm{WF}_{6}$ to deposit tungsten. Once the first $\mathrm{W}$ layer is formed, any gaseous reducing agent such as $\mathrm{H}_{2}$ or silane reduces $\mathrm{WF}_{6}$ and assures a steady growth of $\mathrm{W}$. On the other hand, no reduction of $\mathrm{WF}_{6}$ precursor occurrs on $\mathrm{SiO}_{2}$ surface since $\mathrm{Si}$ in $\mathrm{SiO}_{2}$ is totally oxidized, preventing W growth $^{6,7}$.

For the selective CVD of metallic aluminum on $\mathrm{Si} / \mathrm{SiO}_{2}$ patterned samples using triisobutylaluminum (TIBA), the reaction of the precursors with $\mathrm{SiO}_{2}$ surfaces led to a creation of a monolayer of $\mathrm{C}$ and $\mathrm{Al}$ that doesn't react with additional precursor ${ }^{8}$. Yet, on the non-growth surface, the precursor either does not stick directly or it reacts and saturates the surface with a relatively stable layer blocking the reaction of additional precursor coming on it ${ }^{9}$.

Moreover, area selective deposition by CVD can be enhanced by adding an inhibitor to the process that passivates one surface and promotes deposition on another. as it is the case for $\mathrm{MoC}_{\mathrm{x}} \mathrm{N}_{\mathrm{y}}, \mathrm{Fe}$ and $\mathrm{Ru}$ thin films deposited selectively on metal surfaces vs oxide surfaces ${ }^{10}$ or the selective deposition of $\mathrm{Co}$ thin film on acidic oxides versus basic oxides when a $\mathrm{NH}_{3}$ flow is added to the precursors ${ }^{11}$. Another AS-CVD approach is to introduce a 4-octyne "co-adsorbate" species during the process. Those species bind strongly to $\mathrm{Cu}$ surfaces compared to $\mathrm{SiO}_{2}$ surfaces blocking the growth of $\mathrm{ZrO}_{2}$ film on $\mathrm{Cu}^{12}$.

For AS-ALD, the passivation of the non-growth surface results from a pretreatment prior to the film deposition process. This can be done either by using organic films such as self-assembled monolayers (SAMs) ${ }^{13-16}$ or polymers ${ }^{17}$ that preferentially react with a certain type of surfaces (metal or oxides) inhibiting any film growth, or by exposing the surface to an $\mathrm{H}_{2}$ plasma ${ }^{18}$. However, many constraints face this methodology, such as the adsorption of the precursor on the inhibitor, or losing the inhibitor molecules after few cycles ${ }^{19}$. Current ASD research focuses on alternating deposition and etching to get the desired selective deposition. The resulting supercycle method benefits from the nucleation delay between two different surfaces to obtain the first selective film deposited and then introduce the etch step to reinitiate a new nucleation delay ${ }^{20,21}$.

In this work, we explore the use of a low temperature variant of CVD, namely Plasma-Enhanced Chemical Vapour Deposition (PECVD) to achieve ASD. In recent work, area selective PECVD has been demonstrated on $\mathrm{SiN}_{\mathrm{x}}$ versus $\mathrm{AlO}_{\mathrm{x}}$ surfaces by using an $\mathrm{Ar} / \mathrm{SiF}_{4} / \mathrm{H}_{2}$ gas mixture ${ }^{22}$. In this paper we use the same plasma chemistry, and aim to identify the underlying causes (physical or chemical) behind the area selective PECVD of microcrystalline silicon films on $\mathrm{SiO}_{\mathrm{x}} \mathrm{N}_{\mathrm{y}} \mathrm{vs} \mathrm{AlO}_{\mathrm{x}}$.

\section{Experimental Description}

\section{A. Sample preparation}


$\mathrm{AlO}_{\mathrm{x}}$ was deposited on silicon substrates by Atomic Layer Deposition (ALD) using trimethylaluminum (TMA) and water as precursors (500 ALD cycles). A part of the the $\mathrm{AlO}_{\mathrm{x}}$ coated Silicon wafer was then masked by a piece of scrap silicon, and a $\mathrm{SiO}_{\mathrm{x}} \mathrm{N}_{\mathrm{y}}$ layer was deposited using an Electron Cyclotron Resonance (ECR-) PECVD system. The resulting sample is represented schematically in figure 1.

\section{B. $\mathrm{Ar} / \mathrm{SiF}_{4} / \mathrm{H}_{2}$ PECVD}

The area-selective deposition of $\mu \mathrm{c}-\mathrm{Si}: \mathrm{H}$ thin films was performed in the ATOS PECVD reactor. ATOS is a Radio Frequency-Capacitively Coupled Plasma (RF-CCP) system with a load lock, and which is equipped with an in-situ ellipsometer (J.A Woollam RC2). Spectra were measured for the range from $1.3 \mathrm{eV}-5 \mathrm{eV}$ and modelled using the Tauc-Lorentz dispersion formula. The interelectrode distance is $25 \mathrm{~mm}$ and the working pressure is 1.7 Torr. Each electrode is heated independently but were both set to identical temperatures for all experiments. The $\mathrm{Ar} / \mathrm{SiF}_{4} / \mathrm{H}_{2}$ flow rates used were 200/20/14 sccm. For some samples, an a-Si:H "capping" layer was deposited after the selective deposition process for XPS studies (see fig.1).

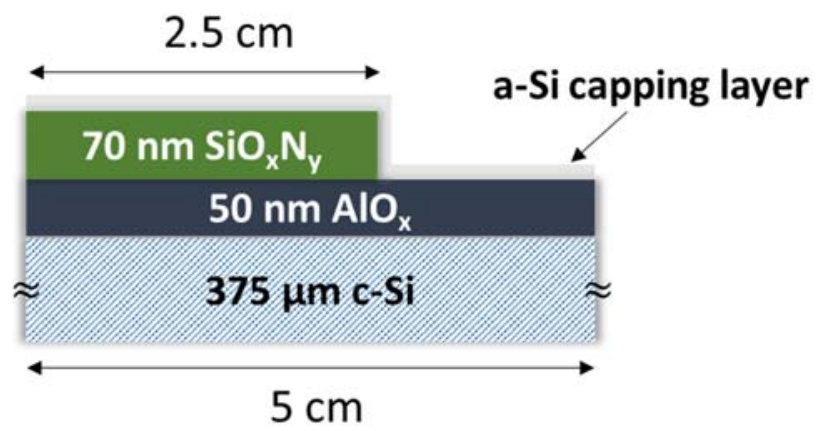

FIG. 1. Schematic representation of sample substrates. The amorphous silicon (a-Si) capping layer is $10 \mathrm{~nm}$ thick.

\section{TEM and EDX sample preparation}

Transmission Electron Microscopy (TEM) and Energy Dispersive X-Ray (EDX) analysis were performed on a Titan Themis transmission electron microscope operating at $200 \mathrm{kV}$ equipped with a Cs aberration probe corrector and a Super X that allows chemical analyses of light and heavy elements with a spatial resolution in the nm range. For this, cross-sectional sample lamellas have been prepared using a standard lift-out procedure in a Focused Ion Beam dual beam microscope (FIB, FEI-Scios Dual Beam). For the chemical analyses by EDX, we have chosen the following as elements of interest: silicon (with an ionization edge at $\mathrm{K} \alpha=1.74 \mathrm{KeV}$ ), oxygen $(\mathrm{K} \alpha=0.523$ $\mathrm{KeV})$, aluminum $(\mathrm{K} \alpha=1.48 \mathrm{KeV})$, fluorine $(\mathrm{K} \alpha=0.67 \mathrm{KeV})$ and nitrogen $(\mathrm{K} \alpha=0.39 \mathrm{KeV})$. Carbon and platinum protective layers have been deposited on top of the sample prior to the FIB milling process in order to prevent $\mathrm{Ga}$ ion implantation during the milling process. 
XPS analysis (surface and profiling)

X-ray Photoelectron Spectroscopy (XPS) measurements were carried out at Institut Lavoisier Versailles on a Thermofisher Scientific NEXSA spectrometer equipped with a monochromated $\mathrm{Al}-\mathrm{K} \alpha$ anode $(1486.6 \mathrm{eV})$ and a dual flood gun (low energy electron and ion). Despite the use of charge compensation, a differential charging effect could not be avoided. Consequently, the spectra are presented without any specific energy scale recalibration, and should therefore be interpreted comparatively. High energy resolution spectral windows of interest were recorded with a $400 \mu \mathrm{m}$ spot size. The photoelectron detection was performed using a constant analyzer energy (CAE) mode (20 eV pass energy) and a $0.1 \mathrm{eV}$ energy step.

XPS depth profiling required the use of the Thermofisher Scientific MAGCIS dual-beam ion gun. Monoatomic argon $(\mathrm{Ar}+)$ ions were accelerated to reach the sample with a kinetic energy of 2000 $\mathrm{eV}$ and an angle of $30^{\circ}$ from the surface normal. The thin films were irradiated on a square area of $2 \times 2 \mathrm{~mm}^{2}$.

Quantification was performed based on the A12p, Si2p, C1s, N1s, O1s, F1s photopeak areas after a Shirley type background subtraction using the Thermofisher Scientific Avantage $\odot$ software and its "ALTHERMO1" library as sensitivity factor collection. A Gaussian-Lorentzian convolved function with $\mathrm{L} / \mathrm{G}=30 \%$ was used for the XPS Al2p spectra reconstruction. The spin-orbit coupling Al2 $\mathrm{p}_{1 / 2}-\mathrm{Al} 2 \mathrm{p}_{3 / 2}$ was set to $0.44 \mathrm{eV}$.

\section{Selectivity Process Window}

\section{A. Selective deposition process for $\mathrm{Ar} / \mathrm{SiF}_{4} / \mathrm{H}_{2}$ PECVD}

Through many trials, a process window for selective deposition was determined. Reliable selectivity is obtained when a process condition consisting of $8 \mathrm{~W}$ RF power and a substrate/electrode temperature of $10{ }^{\circ} \mathrm{C}$ were used, a gas flow mixture of $\mathrm{Ar} / \mathrm{SiF}_{4} / \mathrm{H}_{2}=200 / 20 / 14$ sccm and a total pressure of 1.7 Torr. The results shown in this section are for such plasma conditions.

During the plasma process, deposition was monitored by in-situ ellipsometry; ellipsometric spectra were acquired once every second and were fitted using the CompleteEASE software in the following way: the underlying substrate layers were first measured and modelled prior to plasma ignition, and then left unchanged during the subsequent modelling during growth. The deposited silicon layer is modeled using a Tauc Lorentz (TL) dispersion function and a surface roughness, represented by a mixture of $50 \%$ of $\mu \mathrm{c}-\mathrm{Si}$ with $50 \%$ of void using Bruggeman Effective Medium Approximation. The TL optical constants were chosen to fit with the thickest layer, present at the end of deposition. Then, the thicknesses of the parameterized layer (as well as the surface roughness) were fitted starting from the end-point, then progressing backwards in time, allowing only the thickness of the layer to change.

For the same plasma conditions, in-situ ellipsometric spectra of different surfaces were measured in separate runs (with final spectra confirmed ex-situ). Figure 2 shows the thickness of deposited silicon with time on $\mathrm{SiO}_{\mathrm{x}} \mathrm{N}_{\mathrm{y}}, \mathrm{AlO}_{\mathrm{x}}$, and aluminum surfaces. Aluminum surfaces were prepared by 
coating a $50 \mathrm{~nm}$ layer of aluminum on a silicon substrate using thermal evaporator. Silicon growth only occurs on the $\mathrm{SiO}_{x} \mathrm{~N}_{y}$ layer, while no deposition occurred on the $\mathrm{AlO}_{\mathrm{x}}$ or $\mathrm{Al}$ surfaces. As a result, a $55 \mathrm{~nm}$ thick silicon film is deposited selectively on $\mathrm{SiO}_{\mathrm{x}} \mathrm{N}_{\mathrm{y}}$ area versus $\mathrm{AlO}_{\mathrm{x}}$ area (see sample in fig.1). Moreover, the optical constants of the silicon layer as well as the shape of the roughness evolution is consistent with microcrystalline silicon growing on top of $\mathrm{SiO}_{\mathrm{x}} \mathrm{N}_{\mathrm{y}}{ }^{23,24}$. It should also be mentioned that the Mean Squared Error (MSE) between measured data and modelgenerated data is maximal in the beginning of the process then it decreases with time as the layer becomes denser and less rough.

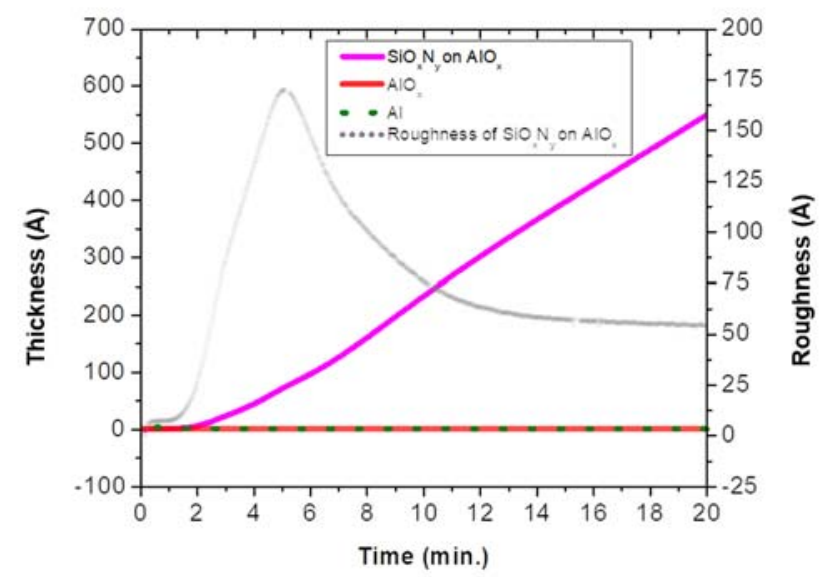

FIG. 2. Silicon layer thickness and surface roughness with time measured by in-situ ellipsometry on $\mathrm{SiO}_{\mathrm{x}} \mathrm{N}_{\mathrm{y}}, \mathrm{AlO}_{\mathrm{x}}$ and $\mathrm{Al}$ surfaces.

\section{B. Non-selective deposition process for $\mathrm{Ar} / \mathrm{SiF}_{4} / \mathrm{H}_{2} \mathrm{PECVD}$}

Performing a plasma process outside of the selectivity process window (mentioned in the previous section) results in selectivity breakdown, manifested as silicon growth on an $\mathrm{AlO}_{\mathrm{x}}$ surface. Specifically, deposition occurs on an $\mathrm{AlO}_{\mathrm{x}}$ surface when increasing the $\mathrm{RF}$ power (from $8 \mathrm{~W}$ to $15 \mathrm{~W}$ ) or the temperature of the electrodes (from $100^{\circ} \mathrm{C}$ to $175^{\circ} \mathrm{C}$ ). In the example presented below, $\mathrm{Ar} / \mathrm{H}_{2} / \mathrm{SiF}_{4}$ gas flows and pressure are set the same as in the previous experiment, 200/20/14 sccm and 1.7 Torr respectively. Selectivity is lost for $15 \mathrm{Watts} / 100^{\circ} \mathrm{C}$ and for $10 \mathrm{~W} / 175^{\circ} \mathrm{C}$, as shown in figure 3. Furthermore, it is clear that deposition on the $\mathrm{AlO}_{\mathrm{x}}$ area evolves very differently than on $\mathrm{SiO}_{\mathrm{x}} \mathrm{N}_{\mathrm{y}}$, as the roughness and thickness display very distinct, abrupt changes and nonmonotonicity, respectively. It should also be noted that using conditions between 8 and $15 \mathrm{~W}$ and between $100^{\circ} \mathrm{C}$ and $175^{\circ} \mathrm{C}$ results in unpredictable selectivity, which depends on factors including wall conditions, substrate storage time before processing, and even substrate type $\left(\mathrm{AlO}_{\mathrm{x}}\right.$ films on glass will not allow growth, but films on c-Si will). 


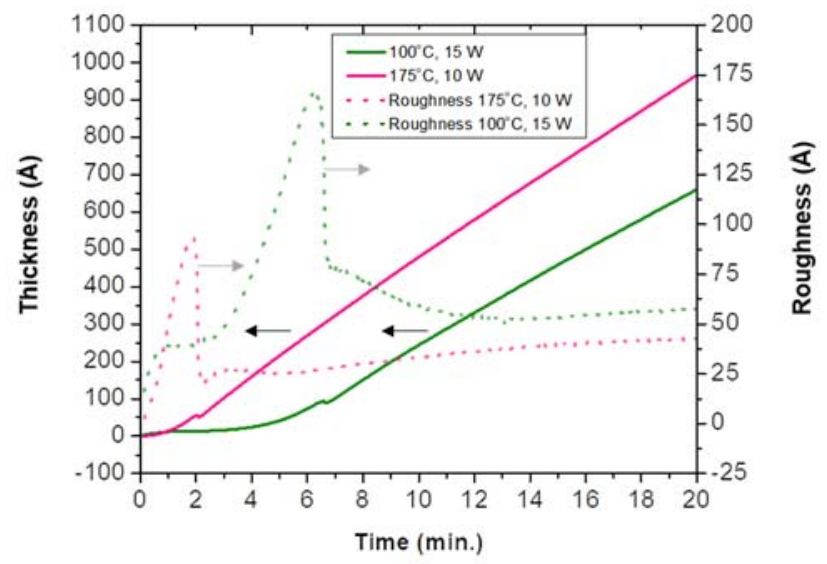

FIG. 3. Microcrystalline silicon ( $\mu \mathrm{c}-\mathrm{Si}: \mathrm{H})$ film thickness with time deposited on Aluminum Oxide $\left(\mathrm{AlO}_{\mathrm{x}}\right)$ for a power of $15 \mathrm{~W}$ (green curve) and a temperature of electrodes of $175^{\circ} \mathrm{C}$ (pink curve).

\section{Physical Origin of Selectivity}

A. TEM Measurements

Structural and chemical characterizations at high resolution were performed using the TEM and Scanning TEM High-Angle Annular Dark Field (STEM-HAADF) imaging mode near the surfaces of two representative samples containing the $\mathrm{SiO}_{\mathrm{x}} \mathrm{N}_{\mathrm{y}}$ and $\mathrm{AlO}_{\mathrm{x}}$ layer.

A STEM-HAADF image on the cross sectional lamella containing first only the $\mathrm{AlO}_{\mathrm{x}}$ area is presented in figure 4. As it can be observed, even though the sample was exposed to the PECVD process using the $\mathrm{SiF}_{4}$ precursor, no trace of any Si layer was observed near the surface (there is only the protective layer, which is a carbon layer deposited prior to the FIB fabrication of the lamella). Another typical finding that can be observed from the HAADF-STEM EDX mapping involves the presence of fluorine, in very small amount, detected primarily on the surface of the $\mathrm{AlO}_{\mathrm{x}}$ layer. It is likely that those $\mathrm{F}$ atoms are bonded to $\mathrm{Al}$ atoms because otherwise fluorine is expected to be difficult to detect once the surface is exposed to the atmosphere for any length of time.

Regarding the second sample, for which a $\mathrm{SiO}_{\mathrm{x}} \mathrm{N}_{\mathrm{y}}$ area was exposed to the plasma process, a TEM image of its corresponding cross-sectional lamella clearly shows the multi-layer stack (figure 5). A closer analysis by Fast Fourier Transform (FFT) on the silicon layer deposited on top of $\mathrm{SiO}_{\mathrm{x}} \mathrm{N}_{\mathrm{y}}$ brings into evidence its microcrystalline structure (as was expected from SE analysis) with crystallite dimensions of few nanometers. Concerning the fluorine presence from the STEMHAADF EDX chemical analysis, one can notice it is present mostly inside the $\mathrm{SiO}_{\mathrm{x}} \mathrm{N}_{\mathrm{y}}$ layer (unlike the $\mathrm{AlO}_{\mathrm{x}}$ layer, where $\mathrm{F}$ was only present at the surface). This must result from the diffusion of $\mathrm{F}$ atoms into this layer during the deposition of $\mu \mathrm{c}-\mathrm{Si}: \mathrm{H}$ (using a $\mathrm{SiF}_{4}$ plasma precursor), as no $\mathrm{F}$ is present in the precursors for $\mathrm{SiO}_{\mathrm{x}} \mathrm{N}_{\mathrm{y}}$ growth. One can also note the absence of $\mathrm{F}$ in the silicon substrate in both cases. 
In order to understand the structure of the $\mathrm{SiO}_{\mathrm{x}} \mathrm{N}_{\mathrm{y}}$ layer, a capping layer of $\mathrm{AlO}_{\mathrm{x}}$ was deposited by ALD, and then the sample was prepared as a lamella, as previously described. Figure 6 shows that the $\mathrm{SiO}_{\mathrm{x}} \mathrm{N}_{\mathrm{y}}$ layer indeed has a columnar structure that most likely allows the in-diffusion of $\mathrm{F}$ during deposition of a layer on top.

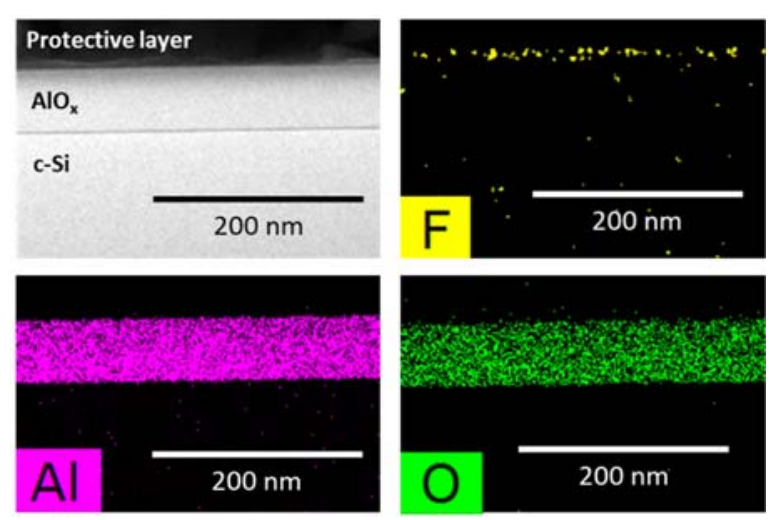

FIG. 4. HAADF image with its corresponding STEM-EDX chemical mapping of $\mathrm{AlO}_{\mathrm{x}}$ area with the chosen element of interest $\mathrm{F}$ (yellow), $\mathrm{Al}$ (pink), and $\mathrm{O}$ (green)
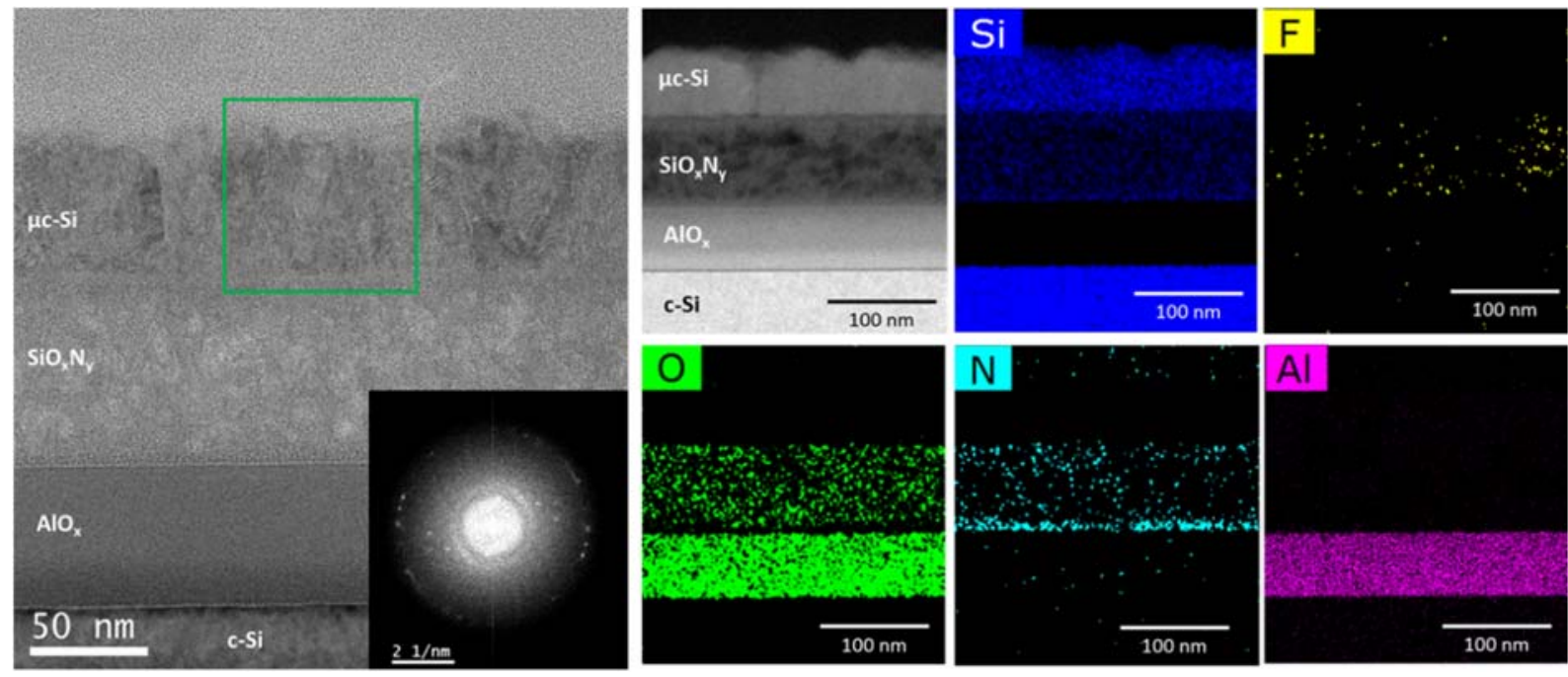

FIG. 5. Bright Field TEM, STEM and EDX chemical analysis of $\mathrm{SiO}_{\mathrm{x}} \mathrm{N}_{\mathrm{y}}$ area. The inset on the right edge of the TEM image is the FFT profile that confirms the microcrystalline structure of the top layer 


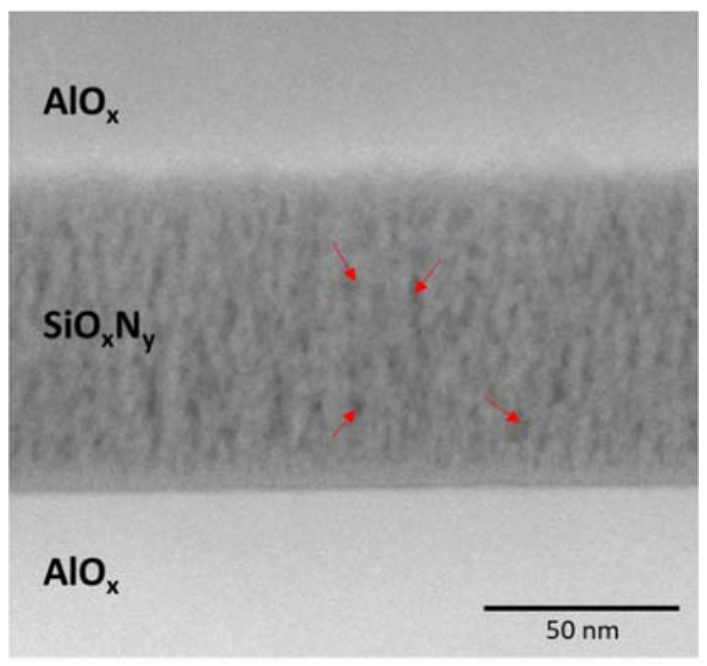

FIG. 6. STEM-HAADF image of $\mathrm{AlO}_{\mathrm{x}} / \mathrm{SiO}_{\mathrm{x}} \mathrm{N}_{\mathrm{y}} / \mathrm{AlO}_{\mathrm{x}}$ showing the columnar growth of $\mathrm{SiO}_{\mathrm{x}} \mathrm{N}_{\mathrm{y}}$ layer

B. XPS Measurements and Analysis

The $\mathrm{SiO}_{\mathrm{x}} \mathrm{N}_{\mathrm{y}}$ and $\mathrm{AlO}_{\mathrm{x}}$ surface chemistries resulting from the selective deposition process with $\mathrm{Ar} / \mathrm{SiF}_{4} / \mathrm{H}_{2}$ plasma (described in the experimental section) have been investigated using X-ray Photoelectron Spectroscopy (XPS). In order to preserve the integrity of the chemical information and minimize surface contamination, an encapsulation layer consisting of $10 \mathrm{~nm}$ of amorphous silicon layer was deposited on top, using a $\mathrm{SiH}_{4} / \mathrm{H}_{2}$ plasma. The chemical composition at the buried interfaces was determined by sequential depth profiling of each stack, and the corresponding indepth overall atomic percentage profiles are presented in Figure 7. For both $\mathrm{SiO}_{\mathrm{x}} \mathrm{N}_{\mathrm{y}}$ and $\mathrm{AlO}_{\mathrm{x}}$ areas, $\mathrm{C}$ and $\mathrm{O}$ are present at the initial, extreme surface and correspond to the adventitious carbon layer inherent to ambient air exposure. No trace of fluorine is observed within the $\mu \mathrm{c}-\mathrm{Si}: \mathrm{H}$ layer. This means that the $\mathrm{F}$ from the $\mathrm{SiF}_{4}$ precursor is fully scavenged by $\mathrm{H}$ during the growth process, at least to a level below the XPS detection threshold. This result is consistent with previous studies ${ }^{25,26}$. All the different interfaces are sharp and clearly identified. Concerning the $\mathrm{SiO}_{\mathrm{x}} \mathrm{N}_{\mathrm{y}}$ area, the $\mu \mathrm{c}-\mathrm{Si}: \mathrm{H} / \mathrm{SiO}_{\mathrm{x}} \mathrm{N}_{\mathrm{y}}$ interface is reached after $370 \mathrm{~s}$ sputtering. During the profiling of this $\mathrm{SiO}_{\mathrm{x}} \mathrm{N}_{\mathrm{y}}$ layer the $\mathrm{O}$ and $\mathrm{Si}$ contents are roughly constant although a $\mathrm{F}$ gradient (12 at.\% maximum value) is visible, negatively correlated to the $\mathrm{N}$ distribution. This confirms the trend evidenced by the STEM-EDX analysis, also showing $\mathrm{F}$ incorporation. For the $\mathrm{AlO}_{\mathrm{x}}$ area, $\mathrm{F}$ is only localized at the a-Si $/ \mathrm{AlO}_{\mathrm{x}}$ interface and reaching a content of 18 at $\%$. 


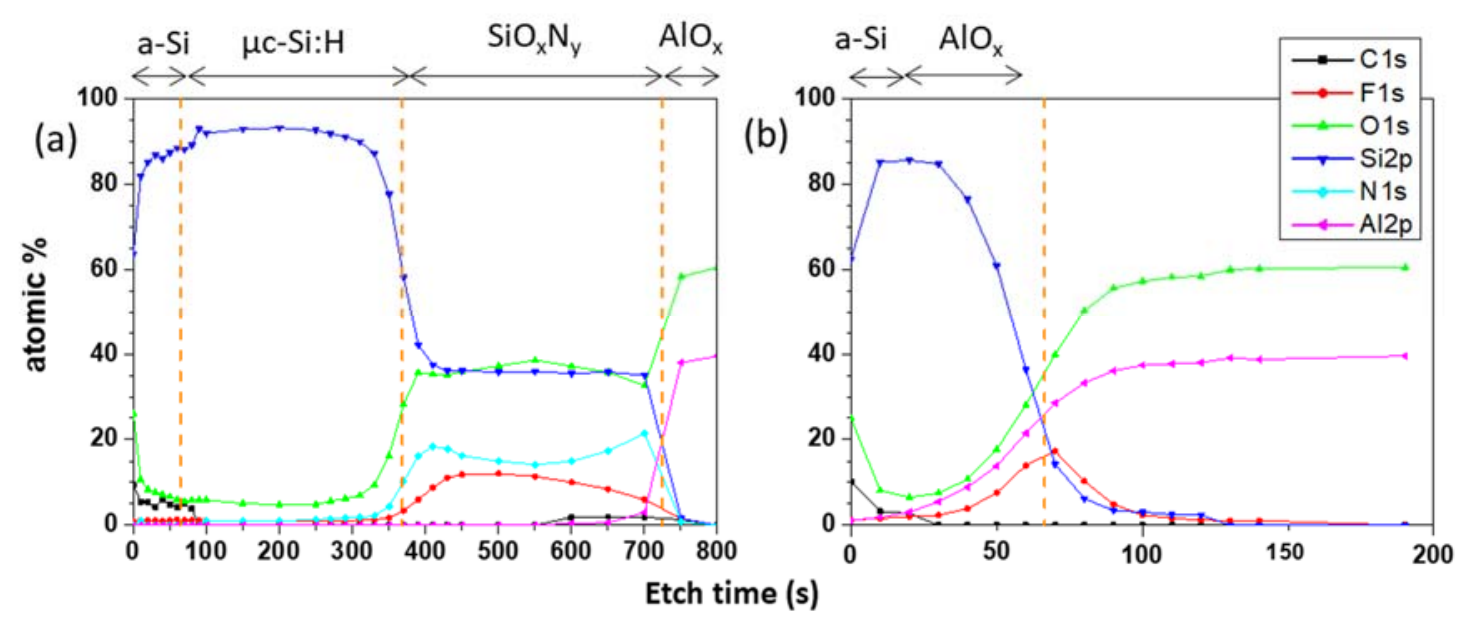

FIG. 7.XPS depth profiles of (a) $\mathrm{SiO}_{\mathrm{x}} \mathrm{N}_{\mathrm{y}}$ and (b) $\mathrm{AlO}_{\mathrm{x}}$ areas on c-Si substrate. (Note: $\mathrm{x}$ axis scales are not the same for both graphs).

In addition to these elemental chemical composition profiles, a fine XPS analysis was conducted using high-energy-resolution spectral windows in order to access information on the chemical environments of each element. We will focus on the $\mathrm{AlO}_{\mathrm{x}}$ area where no deposition occurs. The evolution of the A12p peak during profiling is shown Figure 8 (a). Note that the a-Si layer is very thin (less than the escape depth of Al2p photoelectrons), so the Al is detected even before sputtering. The A12p peak position is progressively shifted toward lower binding energies with increase sputtering time, i.e. when probing the bulk $\mathrm{AlO}_{\mathrm{x}}$ layer. This behavior is consistent with the presence of a more electronegative element at the surface compared to the bulk and clearly suggests the formation of Al-F bonds at the surface of the AlOx layer. Indeed, a fit of the Al2p photopeak representative of the $\mathrm{AlO}_{\mathrm{x}}$ surface $(70 \mathrm{~s}$ etching time on the profile of Figure 7 (b)) is presented in Figure 8 (b), and requires two doublets, attributed to Al-O and Al-F bonds, whose energy positions are shifted by $1.5 \mathrm{eV}$. The expected energy difference is around $2.0 \mathrm{eV}$ for pure $\mathrm{Al}_{2} \mathrm{O}_{3}$ and $\mathrm{AlF}_{3}$ compounds ${ }^{27}$ suggesting a rather mixed Al-O-F environment at the surface of the $\mathrm{AlO}_{\mathrm{x}}$ layer. $\mathrm{An} \mathrm{Al}-\mathrm{O} / \mathrm{Al}-\mathrm{F}$ ratio of 2.66 is estimated, leading to a ratio of $\mathrm{F} / \mathrm{Al}=2.9$. This indicates that the amount of $\mathrm{F}$ exceeds the number of $\mathrm{Al}$ sites available, so in fact only a part of the $\mathrm{F}$ is really bonded, and the rest is likely adsorbed on top. 

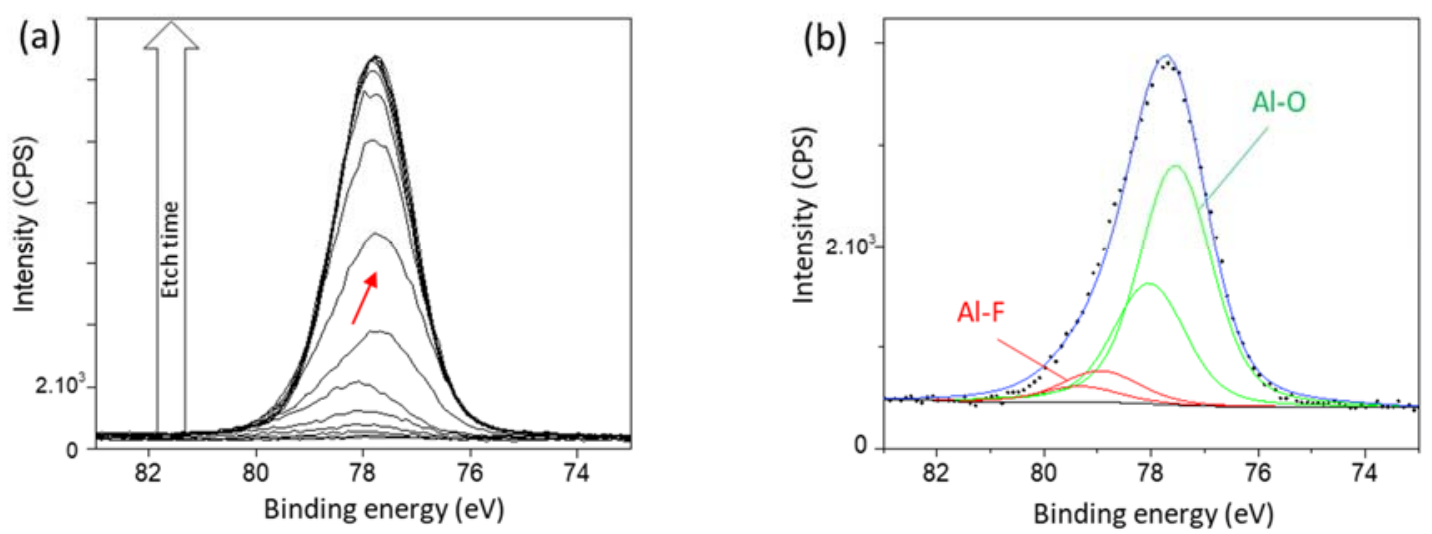

FIG. 8. (a) Al2p photopeak evolution with etching time for a-Si/A1O $/ \mathrm{c}_{\mathrm{c}} \mathrm{Si}$ sample and (b) typical $\mathrm{A} 12 \mathrm{p}$ fit at the $\mathrm{AlO}_{\mathrm{x}}$ surface, i.e. 70 s etching time.

The same analyses have been carried out on two other samples: one before any plasma process (as a reference, labelled "Ref $\mathrm{AlO}_{\mathrm{x}}$ ") and another with a selective deposition process but without any capping layer (labelled "w/o a-Si cap). Figure 9 shows the A12p photopeaks for those three samples. It is clear that after exposure to the $\mathrm{Ar} / \mathrm{SiF}_{4} / \mathrm{H}_{2}$ plasma, a new contribution at high binding energy, attributed to Al-F bonds, is detected. It is also interesting to note that according to Al$\mathrm{O} / \mathrm{Al}-\mathrm{F}$ atomic percentage ratio, the amount of Al-F bonds is higher on the sample with the a-Si capping (Al-O/Al-F=3.21) compared to the one without $(\mathrm{Al}-\mathrm{O} / \mathrm{Al}-\mathrm{F}=5.44)$. This indicates that some of the Al-F bonds created during the selective deposition process are removed from the $\mathrm{AlO}_{\mathrm{x}}$ surface to allow the deposition of the a-Si:H film. It can be concluded that the more Al-F bonds that are present, the better selectivity is obtained, which is also consistent with lack of deposition on metallic $\mathrm{Al}$ presented in figure 2.

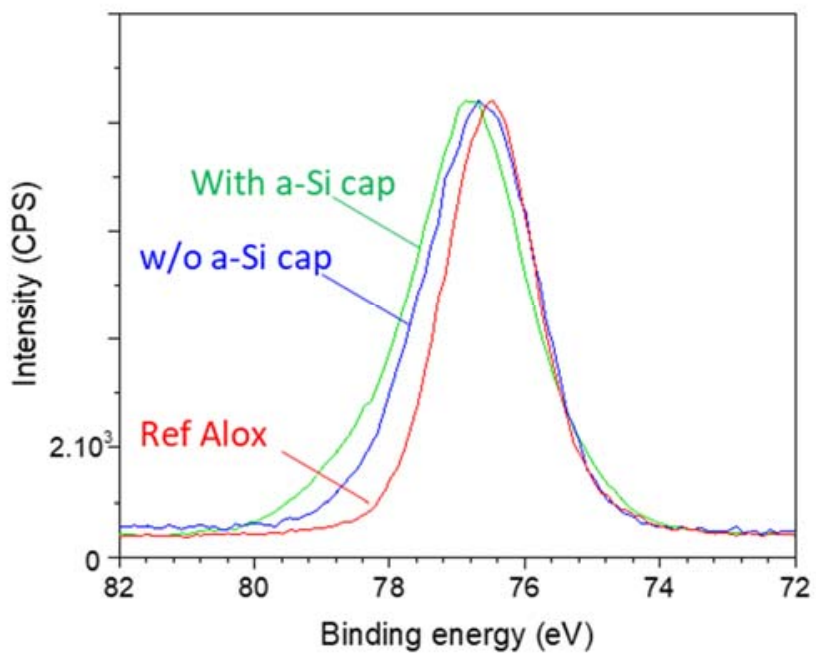


FIG. 9. Comparison of $\mathrm{Al} 2 \mathrm{p}$ photopeaks of $\mathrm{AlO}_{\mathrm{x}}$ area before plasma process (red) and after (green with a-Si capping layer, and blue without).

\section{CONCLUSIONS}

In this work, we have attempted to identify the origins of area selective deposition of silicon by PECVD when comparing $\mathrm{SiO}_{\mathrm{x}} \mathrm{N}_{\mathrm{y}}$ and $\mathrm{AlO}_{\mathrm{x}}$ surfaces. The TEM and XPS analyses show a very high density of Al-F bonds at the surface of the non-deposition, $\mathrm{AlO}_{\mathrm{x}}$ surface. It can be concluded that Al-F bonds block the deposition of $\mathrm{Si}$, as they form a "chemical" mask that provides selectivity. However, process windows studies show that increased temperature or increased power both weaken this blocking layer. $\mathrm{SiO}_{\mathrm{x}} \mathrm{N}_{\mathrm{y}}$ does not display the presence of this blocking layer. For the samples in this study, $\mathrm{F}$ is incorporated inside the $\mathrm{SiO}_{\mathrm{x}} \mathrm{N}_{\mathrm{y}}$ layer due to its columnar structure, however, this incorporation is not sufficient to prevent the growth of silicon on these surface areas. The model of Al-F bonds preventing the growth of $\mathrm{Si}$ is also consistent with the demonstrated non-growth on an $\mathrm{Al}$ surface. The metric of strong $\mathrm{F}$ bonds with a growth surface may also provide a good prediction mechanism for whether surfaces will be selective to Si growth or not.

In addition, when selectivity breaks down outside of the process window and growth occurs on an $\mathrm{AlO}_{\mathrm{x}}$ surface, the in-situ SE displays unusual features. The plot of Si thickness with time has an inflection point at the moment when the roughness drops dramatically. This could represent a real phenomenon, such as a difference in deposition mode, which starts amorphous with high roughness then continues to be crystalline with smaller roughness. This could also represent a modelling artefact. This is to be confirmed and demonstrated in the future, as the failure of selectivity for certain process conditions could provide further hints to its origins. 


\section{ACKNOWLEDGMENTS}

This activity is funded through the Total-LPICM ANR Industrial Chair "PISTOL" (Contract ANR-17CHIN-0002-01). The authors acknowledge financial support from the French state managed by the

National Research Agency under the Investments for the Future program (ANR-10-EQPX-50, Pole NanoTEM). The authors also acknowledge the support of the Centre Interdisciplinaire de Microscopie électronique de l'X (CIMEX).

\section{References}

${ }^{1}$ G. N. Parsons, and R. D. Clark, Chem. Mater. 2020, 32, 12, 4920-4953

2 M. J. Hampden-Smith and T. T. Kodas, Chem. Vap. Deposition 1995. I, No, 2

${ }^{3}$ A. J. M. Mackus, A. A. Bol and W. M. M. Kessels, Nanoscale, 2014,6, 10941-10960

${ }^{4}$ B.D. Joyce, J.A. Baldrey, Selective epitaxial deposition of silicon, Nature. 195 (1962) 485-486.

${ }^{5}$ F.W. Tausch, A.G. Lapierre, J. Electrochem. Soc. 112 (1965) 706.

${ }^{6}$ J.O. Carlsson, Novel and selective vapor deposition processes, Vacuum. 41 (1990) 1077-1080.

${ }^{7}$ J. Carlsson, M. Boman, J. Vac. Sci. Technol. A Vacuum, Surfaces, Film. 3 (1985) 2298-2302.

${ }^{8}$ D.A. Mantell, J. Vac. Sci. Technol. A Vacuum, Surfaces, Film. 9 (1991) 1045-1050.

${ }^{9}$ W.L. Gladfelter, Chem. Mater. 5 (1993) 1372-1388.

${ }^{10}$ E. Mohimi, Z. V. Zhang, S. Liu, J. L. Mallek, G. S. Girolami, and J. R. Abelson, J. Vac. Sci. Technol. A 36, 041507 (2018)

${ }^{11}$ Z. V. Zhang, S. Liu, G. S. Girolami, and J. R. Abelson, J. Vac. Sci. Technol. A 38, 033401 (2020)

12 T. Suh, Y. Yang, P. Zhao, K. U. Lao, H.-Y. Ko, J. Wong, R. A. DiStasio, and J. R. Engstrom, $\boldsymbol{A C S}$ Applied Materials \& Interfaces 202012 (8), 9989-9999

${ }^{13}$ D. Bobb-Semple, K. L. Nardi, N. Draeger, D. M. Hausmann, and S. F. Bent, Chem. Mater. 2019, $31,1635-1645$

${ }^{14}$ R. Wojtecki, M. Mettry, N.F. Fine Nathel, A. Friz, A. De Silva, N. Arellano, H. Shobha, $\boldsymbol{A C S}$ Appl. Mater. Interfaces. 10 (2018) 38630-38637.

${ }^{15}$ A. P. Hinckley, M. M. Driskill, and A. J. Muscat, ACS Appl. Nano Mater. 2020, 3, 3185-3194

${ }^{16}$ J. Soethoudt, Y. Tomczak, B. Meynaerts, B. T. Chan, and A. Delabie, J. Phys. Chem. C 2020, $124,7163-7173$ 
${ }^{17}$ T. G. Pattison, A. E. Hess, N. Arellano, N. Lanzillo, S. Nguyen, H. Bui, C. Rettner, H. Truong, A. Friz, T. Topuria, A. Fong, B. Hughes, A. T. Tek, A. DeSilva, R. D. Miller, G. G. Qiao, and R. J. Wojtecki, ACS Nano 2020, 14, 4276-4288

${ }^{18}$ E. Stevens, Y. Tomczak, B. T. Chan, E. A. Sanchez, G. N. Parsons and A. Delabie, Chem. Mater. $2018,30,3223-3232$

${ }^{19}$ M. J. M. Merkx, T. E. Sandoval, D. M. Hausmann, W. M. M. Kessels, and A. J. M. Mackus, Chem. Mater. 2020, 32, 3335-3345

${ }^{20}$ R. Vallat, R. Gassilloud, B. Eychenne, C. Vallée, Journal of Vacuum Science \& Technology A 35, $01 \mathrm{~B} 104$ (2017)

${ }^{21}$ M. F. J. Vos, S. N. Chopra, M. A. Verheijen, J. G. Ekerdt, S. Agarwal, W. M. M. Kessels, and A. J. M. Mackus, Chem. Mater. 2019, 31, 3878-3882

${ }^{22}$ G. Akiki, D. Suchet, D. Daineka, S. Filonovich, P. Bulkin, E. V. Johnson, Applied Surface Science 531 (2020) 147305

${ }^{23}$ H. Fujiwara, M. Kondo, and A. Matsuda, Phys. Rev. B 63, 115306 (2001)

${ }^{24}$ H. Fujiwara, M. Kondo, and A. Matsuda, Journal of Applied Physics 93, 2400 (2003)

${ }^{25}$ S. Kasouit, S. Kumar, R. Vanderhaghen, P. Roca i Cabarrocas, I. French, J. Non. Cryst. Solids. 299-302 (2002) 113-117

${ }^{26}$ J.C. Dornstetter, B. Bruneau, P. Bulkin, E. V. Johnson, P. Roca I Cabarrocas, 2014 IEEE 40th Photovolt. Spec. Conf. PVSC 2014. (2014) 2839-2841

${ }^{27}$ J.F. Moulder, W.F. Stickle, P.E. Sobol, K.D. Bomben. Handbook of X-ray photoelectron spectroscopy: a reference book of standard spectra for identification and interpretation of XPS data. Physical Electronics: Eden Prairie, Minnesota, 1995 